\section{Treatment outcomes and prognostic factors in adult patients with secondary hemophagocytic lymphohistiocytosis not associated with malignancy}

\author{
Jae-Ho Yoon, Sung-Soo Park, Young-Woo Jeon, Sung-Eun Lee, Byung-Sik Cho, \\ Ki-Seong Eom, Yoo-Jin Kim, Hee-Je Kim, Seok Lee, Chang-Ki Min, Seok-Goo \\ Cho and Jong Wook Lee
}

Department of Hematology, Catholic Blood and Marrow Transplantation Center, Seoul St. Mary's Hospital, College of Medicine, The Catholic University of Korea, Seoul, Korea
Haematologica 2019

Volume 104(2):269-276

\title{
ABSTRACT
}

$\mathrm{H}$ emophagocytic lymphohistiocytosis is an overwhelming systemic inflammatory process that is life-threatening if not treated appropriately. We analyzed prognostic factors in patients with secondary hemophagocytic lymphohistiocytosis excluding malignancy. In this retrospective study, we analyzed 126 adult cases between 2001 and 2017. Treatment was based on dexamethasone with or without etoposide and cyclosporine. Patients who achieved a complete response by 4 weeks were defined as early stable responders, those who failed to achieve a complete response but showed continuous improvement until 8 weeks were defined as late responders, and those whose conditions waxed and waned until 8 weeks were defined as unstable responders. Patients with hemophagocytic lymphohistiocytosis caused by EpsteinBarr virus had a worse 5-year overall survival compared to those whose disease was secondary to autoimmune disease, other infections, or unknown causes $(25.1 \%$ versus $82.4 \%, 78.7 \%$ and $55.5 \%$, respectively; $P<0.001)$. We observed that the overall response rate at 4 weeks was similar, but decreased at 8 weeks in the Epstein-Barr virus subgroup from $75.5 \%$ to $51.0 \%$, and finally decreased to $30.6 \%$. Multivariate analysis revealed that 8 -week treatment response was the most relevant factor for overall survival. Excluding 8-week response, the presence of EpsteinBarr virus, old age, hyperferritinemia, and thrombocytopenia were associated with poor survival. We established a prognostic model with the parameters: low-risk (score 0-1), intermediate-risk (score 2), and highrisk (score $\geq 3$ ). These groups had 5 -year overall survival rates of $92.1 \%$, $36.8 \%$, and $18.0 \%$, respectively $(P<0.001)$. We found that 8 -week treatment response was a good predictor for overall survival, and that Epstein-Barr virus, old age, thrombocytopenia, and hyperferritinemia were associated with poor survival outcomes. Physicians should take care to identify high-risk patients for appropriate treatment strategies.

\section{Introduction}

Secondary hemophagocytic lymphohistiocytosis (HLH) without a family history or known genetic predisposition is considered a rare clinical condition and its underlying pathophysiological mechanisms have not yet been well elucidated. The distinction between primary HLH and secondary HLH is not clear because of the emergence of new gene defects, and the diagnosis is difficult because the symptoms and signs of HLH overlap with those of other severe conditions such as sepsis, multi-organ failure, and progression of malignancies or rheumatologic disorders. ${ }^{1,2}$ The incidence and prevalence of HLH may, therefore, be under- or overestimated if clinicians lack suspicion of and specific knowledge about HLH, especially in adult patients. ${ }^{3}$

HLH is a life-threatening inflammatory disease, and therefore early diagnosis and urgent treatment, including dexamethasone, cyclosporine, and etoposide, are

\section{Correspondence:}

jwlee@catholic.ac.kr

Received: May 27, 2018.

Accepted: September 11, 2018.

Pre-published: September 13, 2018.

doi:10.3324/haematol.2018.198655

Check the online version for the most updated information on this article, online supplements, and information on authorship \& disclosures: www.haematologica.org/content/104/2/269

\section{(C)2019 Ferrata Storti Foundation}

Material published in Haematologica is covered by copyright. All rights are reserved to the Ferrata Storti Foundation. Use of published material is allowed under the following terms and conditions:

https://creativecommons.org/licenses/by-nc/4.0/legalcode. Copies of published material are allowed for personal or internal use. Sharing published material for non-commercial purposes is subject to the following conditions:

https://creativecommons.org//icenses/by-nc/4.0/legalcode, sect. 3. Reproducing and sharing published material for commercial purposes is not allowed without permission in writing from the publisher. 
important for survival. . $^{4-6}$ However, even when specific therapies are administered promptly, treatment response and overall survival rates remain poor, especially when the condition is associated with malignancies. ${ }^{7,8}$ Poor survival and frequent relapse are common not only in patients with malignancy-associated HLH, but also in those with active Epstein-Barr virus (EBV) infection and in some highrisk patients with HLH of unknown cause. ${ }^{9-11}$ For relapsed or refractory HLH patients, several salvage treatments ${ }^{12-18}$ followed by allogeneic hematopoietic cell transplantation (HCT) are now considered, ${ }^{19-21}$ but many of these patients die of rapid deterioration due to severe sepsis and multiorgan failure. It is, therefore, important for physicians to identify high-risk patients earlier in the course of treatment, and to apply second-line therapy and prepare the patient immediately for allogeneic HCT. However, there are few data identifying relevant prognostic factors and enabling risk-stratification for adult patients with secondary HLH. ${ }^{8,11}$

In this study, we initially analyzed treatment response and survival outcomes among 126 adult patients with non-malignancy-associated secondary HLH according to the underlying causes of the disease. We then assessed factors predictive of treatment response and survival outcome. Finally, we constructed a prognostic model using risk-stratification according to predictive factors in order to identify high-risk patients who should be considered for early second-line therapies, including salvage regimens and allogeneic HCT.

\section{Methods}

\section{Patients}

We retrospectively reviewed records for 165 adult patients who were diagnosed with HLH from 2001 to 2017. All patients pre- sented with fever, some criteria of $\mathrm{HLH} 2004,5,22$ and increased histiocytosis with active hemophagocytosis in bone marrow. Of these 165 patients, we excluded 12 who did not satisfy the full diagnostic criteria and 27 with malignancy-associated HLH (Figure 1 and Online Supplementary Methods for Identification of the causes of HLH). Ultimately, we analyzed 126 patients (median age 45 years, range 15-85 years) with non-malignancy-associated secondary HLH due to several causes. This research was conducted in accordance with Institutional Review Board and Ethics Committee guidelines of the Catholic Medical Center (KC15RISI0863) and the principles of the Declaration of Helsinki.

\section{Parameters associated with hemophagocytic lymphohistiocytosis}

All parameters included in the diagnostic guidelines for HLH were reviewed: fever, splenomegaly, cytopenia affecting at least two lineages, triglycerides, fibrinogen, ferritin, and natural killer (NK)-cell cytotoxic activity. Laboratory findings were serially accessed and the lowest levels were captured for complete blood cell counts, fibrinogen, albumin, and prothrombin time before treatment. The highest levels within 4 weeks after initial treatment were used for ferritin, aspartate aminotransferase, alanine aminotransferase, total bilirubin, lactate dehydrogenase, and triglycerides in order to assess clinical outcomes. We have analyzed NK-cell cytotoxicity by a flow cytometry-based assay since $2012 .{ }^{23}$ We did not check levels of soluble CD25. Thus, the majority of patients enrolled in the current study satisfied at least five out of six criteria for the diagnosis of HLH, excluding the soluble CD25 and NK cytotoxicity criteria. An association with EBV was evaluated by both serology and EBV DNA real-time quantitative polymerase chain reaction (RQ-PCR) analysis (See the Online Supplementary Methods for Identification of the causes of HLH).

\section{Treatments}

Treatment strategies were based on HLH-94 protocols, which consisted mainly of dexamethasone, etoposide, and additional

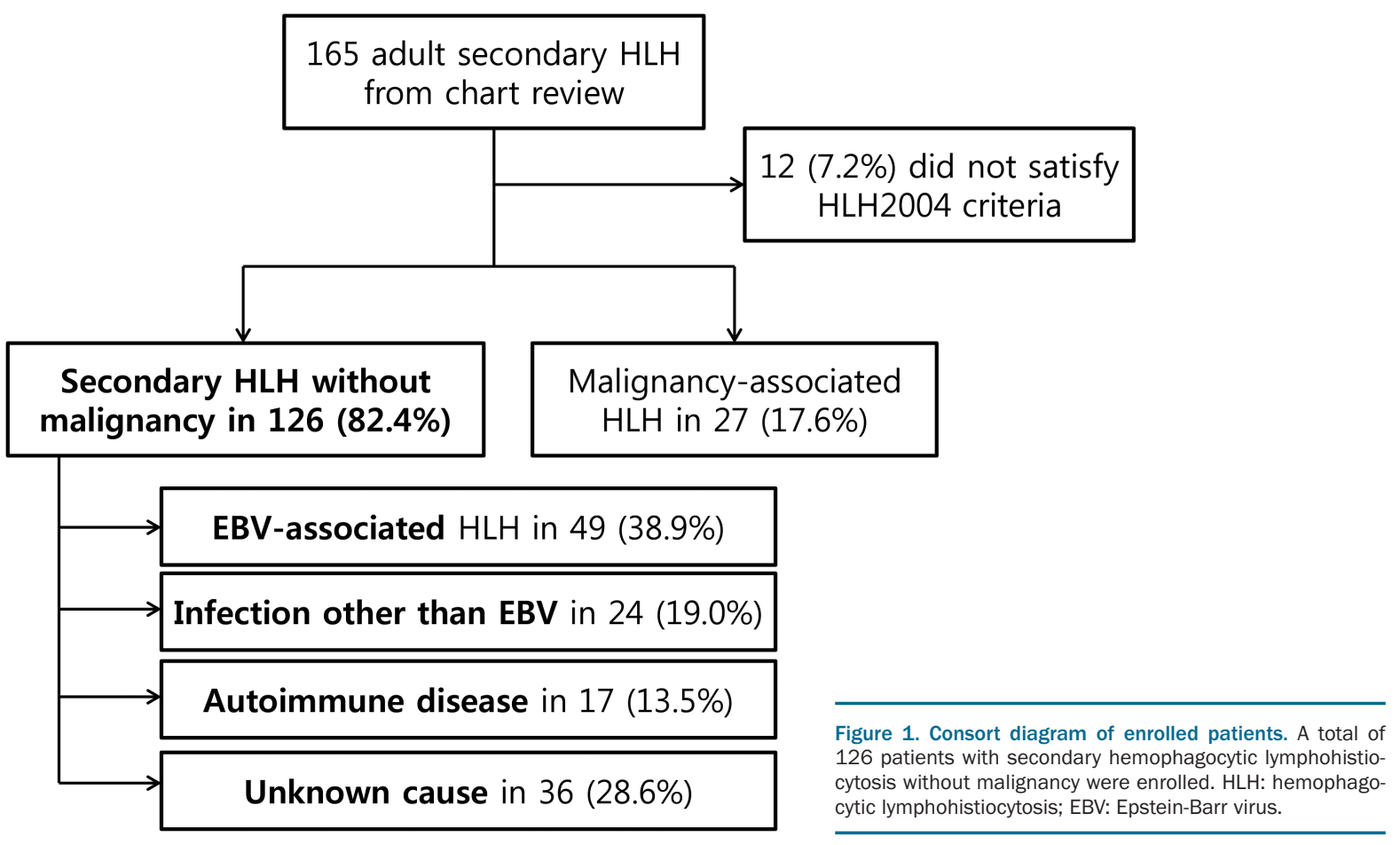


cyclosporine..$^{5,624}$ Final treatment response was evaluated after 8 weeks of induction according to the HLH-94 protocol. Patients exhibiting a complete response at 8 weeks were given maintenance therapy with low-dose steroids and cyclosporine for 2 to 4 more weeks, while patients who did not achieve a complete response or who were positive for EBV according to RQ-PCR (> 3-log) were considered for continuation therapy. If the EBV RQPCR level increased by at least 1-log with features of relapsing $\mathrm{HLH}$, rituximab or alemtuzumab was given. Five patients who relapsed or had refractory disease were treated with allogeneic HCT using fludarabine $\left(30 \mathrm{mg} / \mathrm{m}^{2} /\right.$ day for 5 days), busulfan (3.2 $\mathrm{mg} / \mathrm{kg} /$ day for 2 days), and antithymocyte globulin (ATG, Thymoglobulin ${ }^{\circledR}, 2.5 \mathrm{mg} / \mathrm{kg}$ for 2 days).

\section{Response assessment}

Complete response was defined as resolution of all clinical signs and symptoms, as well as recovery of the complete blood count and normalization of abnormal laboratory findings associated with HLH. Progressive disease was identified when both cytopenia and abnormal laboratory findings remained and partial response was defined when patients achieved either complete blood count recovery alone without normalization of laboratory findings or improvement of $\mathrm{HLH}$-related laboratory findings alone without complete blood count recovery. We evaluated treatment response at 4 and 8 weeks after treatment, and also evaluated dynamic responses according to the response time and disease progression within 8 weeks. Patients with stable complete response at both 4 weeks and 8 weeks were classified as early stable responders, patients who failed to achieve a complete response by 4 weeks but showed continuous response until 8 weeks were classified as late stable responders, patients who showed only transient response and eventually progressed until 8 weeks were defined as unstable responders, and patients exhibiting no response at all were classified as non-responders. Details on the statistical analysis are provided in the Online Supplementary Methods.

\section{Results}

\section{Baseline characteristics of the patients}

The causes of HLH in the 126 patients enrolled in this study were categorized as EBV-associated $(n=49)$, infection other than EBV ( $\mathrm{n}=24)$, and autoimmune disease $(n=17)$. Among the 49 cases of EBV-associated HLH, five were concomitantly related with an autoimmune disease. We were unable to identify related causes in 36 (28.6\%) patients (Figure 1). The baseline characteristics of the patients and their responses to treatment are presented in Table 1. Fever was observed in all patients and 118 $(93.6 \%)$ patients presented with splenomegaly. Infections other than EBV included hepatitis A virus $(n=5)$, cytomegalovirus $(n=2)$, Staphylococcus aureus $(n=3)$, mycoplasma $(n=3)$, parvovirus $(n=3)$, human immunodeficiency virus $(n=2)$, mycobacterium $(n=2)$, malaria $(n=2)$, amebiasis $(n=1)$, anaplasmosis $(n=1)$, Hantaan virus $(n=1)$, herpes simplex virus $(n=1)$, influenza virus $(n=1)$, and enterococcus $(n=1)$. Patients with Kaposi sarcoma caused by human immunodeficiency virus were considered to have malignancy-associated HLH. Autoimmune diseases and similar features included systemic lupus erythematosus $(n=8)$, Kikuchi disease $(n=6)$, Behçet syndrome $(n=2)$, Sjögren syndrome $(n=2)$, Graves disease $(n=1)$, rheumatoid arthritis $(n=1)$, autoimmune hemolytic anemia $(n=1)$, and ulcerative colitis $(\mathrm{n}=1)$. Among the $35 \mathrm{EBV}$-associated
HLH patients with available serology results, seven showed a recent primary infection, five reactivation, and 23 a past infection. In addition, initial bone marrow findings revealed that 36 out of 49 patients $(73.5 \%)$ with EBVassociated HLH had active and frequent hemophagocytosis, while 17 out of the remaining 77 patients $(22.1 \%)$ showed active hemophagocytosis.

\section{Treatment outcomes according to causes of hemophagocytic lymphohistiocytosis}

After excluding four patients (2 with hepatitis A and an unknown cause of HLH who showed a self-limiting disease course, and 2 cases with progressive multi-organ failure before treatment), 122 patients were treated. The HLH-94 protocol was applied in 81 (64.3\%) patients: 23 $(63.8 \%)$ with HLH of unknown cause, 40 (81.6\%) with EBV-HLH, 13 (54.2\%) with an infection other than EBV, and five (29.4\%) with an autoimmune disease). Dexamethasone plus cyclosporine treatment was admin-

Table 1. Baseline characteristics and treatment outcome of patients with non-malignancy-associated secondary HLH ( $n=126)$.

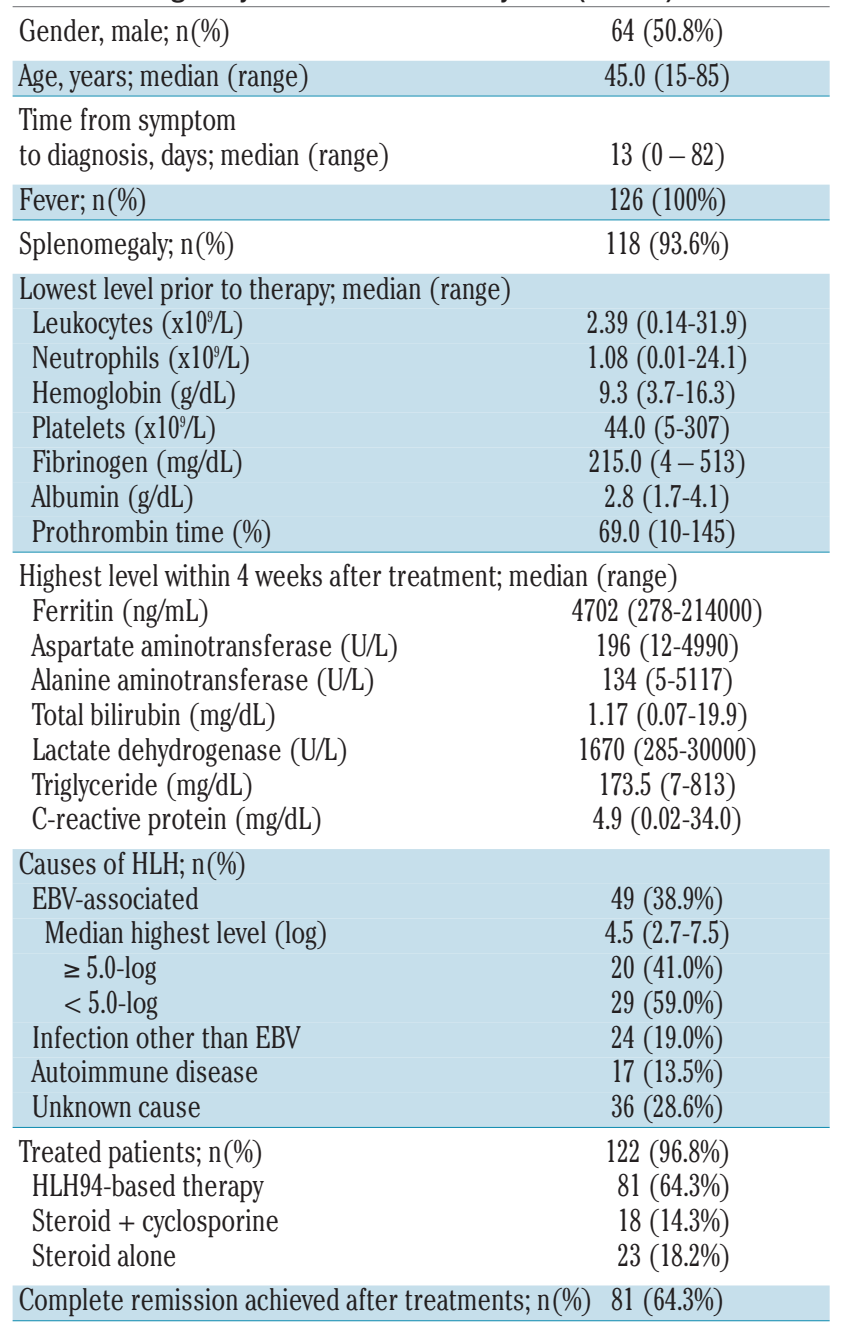

Treatment response at 8 weeks; $\mathrm{n}(\%)$

Early stable responder $\quad 42(34.4 \%)$

Late stable responder $\quad 36(29.5 \%)$

Unstable responder $\quad 19(15.6 \%)$

Non-responder $25(20.5 \%)$

HLH: hemophagocytic lymphohistiocytosis; EBV: Epstein-Barr virus. 
istered to $18(14.3 \%)$ patients, while $23(18.2 \%)$ patients were given dexamethasone alone. Patients who had mild symptoms and improved rapidly were treated with dexamethasone alone and further therapy was not needed. In contrast, we were unable to administer cyclosporine and etoposide to patients with significant deterioration of organ function or a poor general condition. Of the 81 $(64.3 \%)$ patients who achieved a complete response after treatments, 43 achieved this response by 4 weeks after treatment and the other 38 achieved it by 8 weeks or later. Of the 27 patients who relapsed, one relapsed between 4 and 8 weeks and 26 relapsed after 8 weeks during the course of treatment. After relapsing, most of the patients were treated with the HLH-94 protocol again. For relapsed EBV-HLH, we considered rituximab $(\mathrm{n}=6)$ or alemtuzum$a b(n=2)$ concomitantly, and two patients were treated with allogeneic HCT.

With regards to dynamic responses, $42(34.4 \%)$ patients were early stable responders, $36(29.5 \%)$ were late stable responders, $19(15.6 \%)$ were unstable responders, and 25 $(20.5 \%)$ were primary refractory non-responders (Table 1). Detailed responses according to causes of HLH are as follows. In patients with EBV-HLH, the overall response rate (complete plus partial responses) at 4 weeks was $75.5 \%$ (complete response in 16, partial response in 21) but decreased to $51.0 \%$ (complete response in 17, partial response in 8) at 8 weeks, and finally decreased to $30.6 \%$ (complete response in 15). The overall response rates at 4 weeks and 8 weeks for patients with HLH associated with infections other than EBV were $62.5 \%$ (complete response in 10, partial response in 5) and $75 \%$ (complete response in 14, partial response in 4), respectively, for those with autoimmune diseases, $82.3 \%$ (complete response in 9, partial response in 5) and $82.3 \%$ (complete response in 12, partial response in 2), respectively, and for those with $\mathrm{HLH}$ of unknown cause, $66.7 \%$ (complete response in 8 , partial response in 16) and $66.7 \%$ (complete response in 19, partial response in 5), respectively. Patients with HLH associated with an autoimmune disease or infection other than EBV had superior 5 -year overall survival rates (82.4\% and $78.7 \%$, respectively) and lower cumulative incidences

A

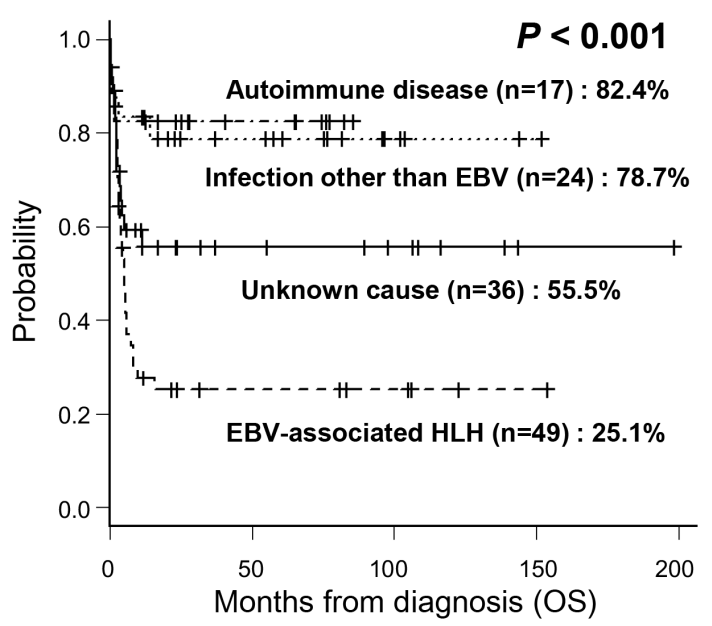

of progression (29.4\% and $22.7 \%$, respectively) compared to those of patients with EBV-associated HLH. The estimated 5-year overall survival rate and cumulative incidence of progression of patients with EBV-associated $\mathrm{HLH}$ were $25.1 \%$ and $77.5 \%$, respectively (Figure 2 ).

\section{Survival outcomes according to treatment response}

Estimated 5-year overall survival rates of patients who achieved a complete response by 4 weeks $(n=43)$ and 8 weeks $(n=62)$ were $82.8 \%$ and $82.7 \%$, respectively, while the overall survival rate of patients who achieved a partial response until 8 weeks ( $n=19$ ) was $68.4 \%$ (Figure 3A,B). As we recognized four subgroups defined according to dynamic treatment response, there were 42 patients in the early stable responder group, 36 in the late stable responder group, 19 in the unstable responder group, and 25 in the non-responder group. Figure $3 \mathrm{C}, \mathrm{D}$ presents the overall survival and cumulative incidence of progression curves of patients divided according to dynamic treatment response. Early stable responders and late stable responders had 5 -year overall survival rates of $80.7 \%$ and $73.7 \%$, respectively, and 5-year cumulative incidences of progression of $20.2 \%$ and $43.1 \%$, respectively, while almost all patients in the unstable and non-responder groups died of disease progression $(P<0.001)$.

\section{Prognostic factors and risk stratification}

We found that most parameters associated with $\mathrm{HLH}$ disease activity were predictive of survival outcomes, and many were correlated with each other. Age was correlated with albumin and alanine aminotransferase levels, EBVassociation with triglyceride and fibrinogen levels, anemia with albumin levels, thrombocytopenia with prothrombin time, total bilirubin and erythrocyte sedimentation rate, and ferritin with prothrombin time, fibrinogen, erythrocyte sedimentation rate, and lactate dehydrogenase levels. Multivariate analyses were performed using age, EBVassociation, thrombocytopenia, ferritin, and dynamic treatment response after excluding correlated parameters (Table 2). Remaining an unstable responder or nonresponder at 8 weeks was the most powerful predictive

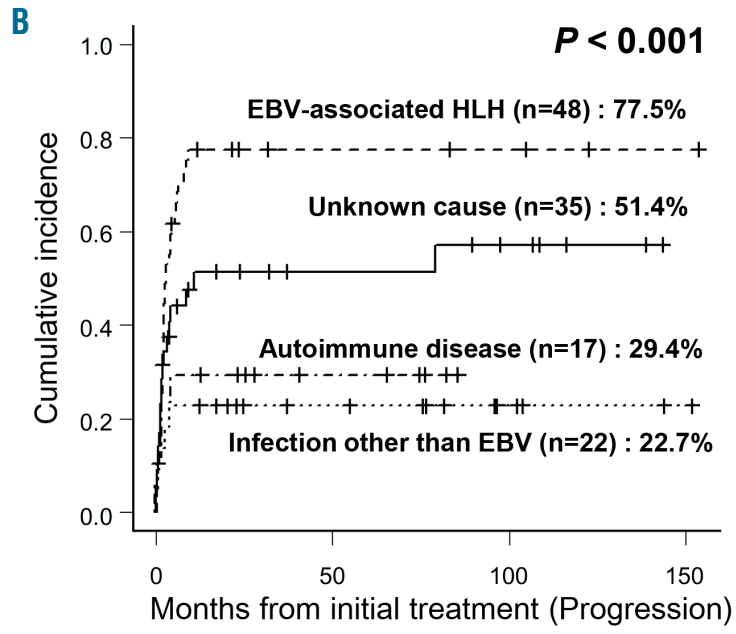

Figure 2. Survival outcomes according to the cause of secondary hemophagocytic lymphohistiocytosis. (A) Comparison of 5-year overall survival rates according to the cause of secondary hemophagocytic lymphohistiocytosis. (B) Comparison of cumulative incidences of progression after treatment according to the cause of secondary hemophagocytic lymphohistiocytosis. OS: overall survival; HLH: hemophagocytic lymphohistiocytosis; EBV: Epstein-Barr virus. 
factor for poor overall survival; age $>45$ years and low platelet counts $\left(<35 \times 10^{9} / \mathrm{L}\right)$ were also significant predictive factors for poor overall survival. When we excluded treatment response as a parameter, age $>45$ years, EBV-association, thrombocytopenia (platelets $<35 \times 10^{9} / \mathrm{L}$ ), and hyperferritinemia $(>20,000 \mathrm{ng} / \mathrm{mL})$ were associated with poor overall survival. All of these factors were also associated with higher cumulative incidences of progression and poor 8-week response (data not shown). We ultimately selected four factors and weighted them based on the hazard ratio: age $>45$ years ( 2 points), EBV-association (1 point), low platelet count $\left(<35 \times 10^{\circ} / \mathrm{L}\right)$ (1 point), and hyperferritinemia (>20,000 $\mathrm{ng} / \mathrm{mL}$ ) (1 point). Using these variables, we performed risk scoring and stratification. The 5 year overall survival rates of low-risk (score $0-1$ ), intermediate-risk (score 2), and poor-risk (score $\geq 3$ ) patients were $92.1 \%, 36.8 \%$, and $18.0 \%$, respectively, while the corresponding 5 -year cumulative incidences of progression were $18.5 \%, 59.4 \%$ and $87.0 \%$ (both $P<0.001$ ) (Figure $4 \mathrm{~A}, \mathrm{~B})$. In the EBV-HLH subgroup, the 5 -year overall survival rate was $59.2 \%$ in early stable responders, $44.4 \%$ in the late responders, and $0.0 \%$ in non-responders.
Multivariate analysis in the EBV-HLH subgroup revealed that maximal EBV RQ-PCR level greater than 5-log, age $>45$ years, and hyperbilirubinemia were associated with poor overall survival

\section{Discussion}

Causes of HLH and the proportions of each identified in the current study differed from those of previous studies, in which the most common cause of secondary HLH was a hematologic malignancy., 3,7,25 Some patients with malignancy-associated HLH die early from rapid deterioration without a suspicion of HLH and their prognosis depends on the outcome of the malignant disease. In the current study we, therefore, analyzed treatment response and prognostic factors for adult secondary HLH after excluding those with malignancy-associated HLH. To the best of our knowledge, this is the largest data set used to analyze prognostic factors in adult patients with secondary HLH without malignancies.

Excluding malignancies, EBV was the most common
A

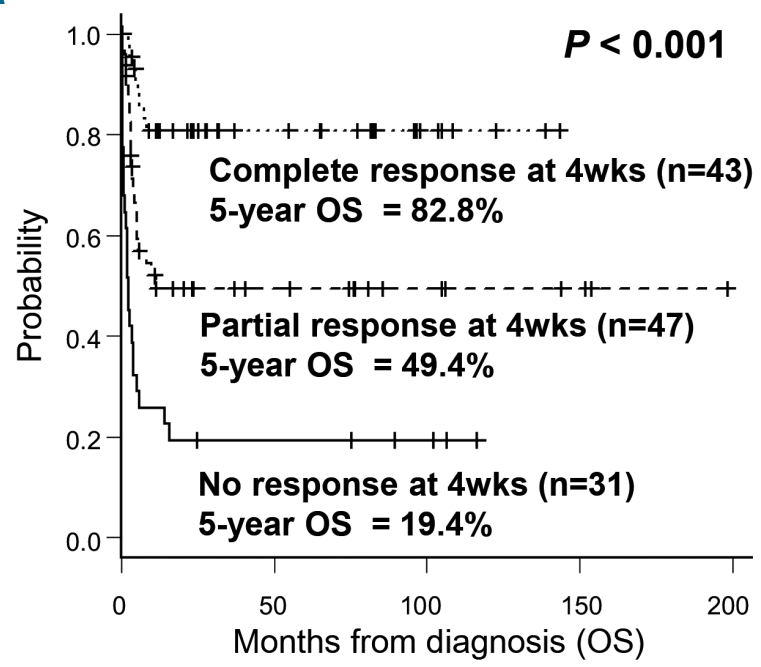

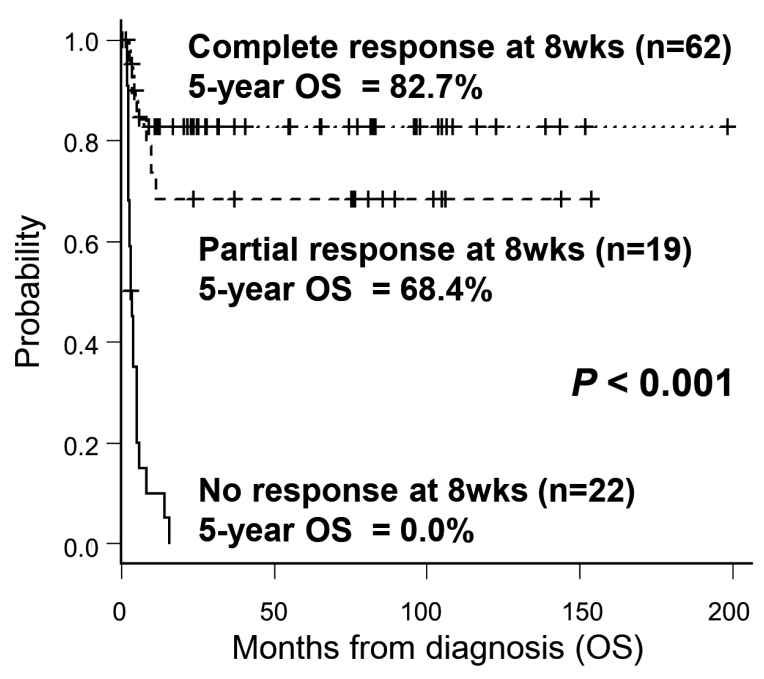

D

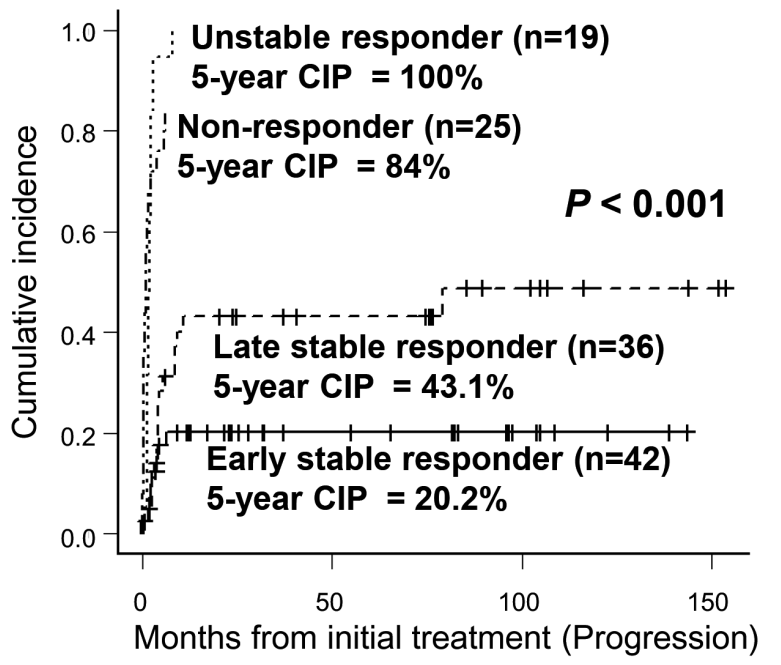

Figure 3. Survival outcomes according to treatment response. (A, B) Five-year overall survival according to treatment response at (A) 4 weeks and (B) 8 weeks. (C,D). Five-year (C) overall survival and (D) cumulative incidence progression according to dynamic treatment response at 8 weeks. OS: overall survival; CIP: cumulative incidence of progression. 
cause of secondary HLH in this study. The prognosis of patients with EBV-associated HLH is expected to be better than that of those with malignancies or primary $\mathrm{HLH}$, but if patients are not treated appropriately, their survival outcomes are dismal. 26,27 Our data revealed that patients with EBV-associated HLH had similar responses to treatment in the early period but many relapsed afterward, which finally resulted in these patients having significantly inferior overall survivals and higher cumulative incidences of progression compared to patients with HLH related to other causes. It is, therefore, important to decide on early salvage treatment, including allogeneic HCT, for poor responders with EBV-associated HLH. Previous reports suggested a role of acyclovir in the management of EBVassociated disease, ${ }^{28,29}$ but no relevant data are available on the additional effects of antiviral therapy. ${ }^{9}$ Salvage treatments include rituximab $b^{12,17,30}$ and alemtuzumab ${ }^{31}$ followed by allogeneic HCT. ${ }^{32,33}$ Although we used rituximab in six patients and alemtuzumab in two in the setting of relapsed disease, none of the patients showed a response to additional therapy suggesting that incorporation of rituximab into the HLH protocol might be an alternative approach as initial treatment in EBV-associated HLH. Of the three patients with relapsed/refractory EBV-HLH treated with allogeneic HCT, one died of relapse, one died of septic pneumonia, and one is alive without relapse.

We calculated survival outcomes of responders and nonresponders at 4 weeks and 8 weeks, respectively, and found that patients who did not achieve at least a stable partial response at 8 weeks had very high mortality. A recent prospective study investigating the effects of a salvage regimen using liposomal doxorubicin applied salvage chemotherapy for refractory patients who were defined as non-responsive to initial therapy at 2 weeks. ${ }^{18}$ However, our data show that patients who failed to achieve a complete response by 4 weeks after treatment could still achieve long-term survival if they exhibited a continuous and stable response until 8 weeks. The HLH-94 protocol recommends continuation therapy when disease is active at 8 weeks after initial therapy, and our study population included patients who proceeded to continuation therapy. Among our 21 patients who were given continuation therapy, 16 additional patients ultimately achieved a complete response and two of these patients were treated with allogeneic HCT. There are no data comparing survival between patients receiving continuation therapy and other salvage regimens, or on the proper timing for allogeneic HCT, especially in patients with EBV-HLH. However, as our data indicate that the course of EBV-HLH after relapse is very progressive, urgent preparation for allogeneic HCT is recommended. We also identified that the risk of relapse among patients with EBV-HLH was higher in those with an age $>45$ years, maximal EBV RQPCR higher than 5-log, and hyperbilirubinemia.

Apart from non-responders at 8 weeks, who have a particularly poor outcome, we further identified high-risk

Table 2. Univariate and multivariate analyses for parameters affecting overall survival in non-malignancy-associated HLH.

\begin{tabular}{|c|c|c|c|c|c|c|}
\hline & \multirow{2}{*}{\multicolumn{2}{|c|}{ Univariate analysis }} & \multicolumn{4}{|c|}{ Multivariate analysis } \\
\hline & & & \multicolumn{2}{|c|}{ Treatment response included } & \multicolumn{2}{|c|}{ Treatment response excluded } \\
\hline & 5-year OS & $\boldsymbol{P}$ & HR & $P$ & HR & $\mathbf{P}$ \\
\hline $\begin{array}{l}\text { Age }>45 \text { years old } * * \\
(\mathrm{n}=61,49.4 \%)\end{array}$ & $\begin{array}{c}26.8 \% \\
\text { (vs. } 74.9 \%)\end{array}$ & $<0.001^{*}$ & $\begin{array}{c}2.54 \\
(1.4-4.7)\end{array}$ & $0.003^{*}$ & $\begin{array}{c}3.38 \\
(1.9-6.1)\end{array}$ & $<0.001^{*}$ \\
\hline $\begin{array}{l}\text { EBV-associated** } \\
(\mathrm{n}=49,45.9 \%)\end{array}$ & $\begin{array}{c}25.1 \% \\
\text { (vs. } 69.3 \%)\end{array}$ & $<0.001^{*}$ & & & $\begin{array}{c}2.16 \\
(1.2-3.8)\end{array}$ & $0.006^{*}$ \\
\hline $\begin{array}{l}\text { Hemoglobin }<9.0 \mathrm{~g} / \mathrm{dL} \\
(\mathrm{n}=47,42.5 \%)\end{array}$ & $\begin{array}{c}38.7 \% \\
\text { (vs. } 75.6 \%)\end{array}$ & $<0.001^{*}$ & & & & \\
\hline $\begin{array}{l}\text { Platelet count }<35 \times 10^{9} / \mathrm{L}^{* *} \\
(\mathrm{n}=47,36.8 \%)\end{array}$ & $\begin{array}{c}32.8 \% \\
\text { (vs. } 64.7 \%)\end{array}$ & $<0.001^{*}$ & $\begin{array}{c}1.99 \\
(1.1-3.5)\end{array}$ & $0.016^{*}$ & $\begin{array}{c}2.20 \\
(1.3-3.8)\end{array}$ & $0.004^{*}$ \\
\hline $\begin{array}{l}\text { Alanine aminotransferase }>165 \mathrm{U} / \mathrm{L} \\
(\mathrm{n}=55,32.2 \%)\end{array}$ & $\begin{array}{c}67.7 \% \\
\text { (vs. } 40.6 \%)\end{array}$ & $0.0055^{*}$ & & & & \\
\hline $\begin{array}{l}\text { Bilirubin }>1.6 \mathrm{mg} / \mathrm{dL} \\
(\mathrm{n}=51,43.7 \%)\end{array}$ & $\begin{array}{c}30.1 \% \\
\text { (vs. } 68.5 \%)\end{array}$ & $<0.001^{*}$ & & & & \\
\hline $\begin{array}{l}\text { Albumin }<3.0 \mathrm{~g} / \mathrm{dL} \\
(\mathrm{n}=76,49.4 \%)\end{array}$ & $\begin{array}{c}34.2 \% \\
\text { (vs. } 80.8 \%)\end{array}$ & $<0.001^{*}$ & & & & \\
\hline $\begin{array}{l}\text { Triglycerides }>200 \mathrm{mg} / \mathrm{dL} \\
(\mathrm{n}=50,43.7 \%)\end{array}$ & $\begin{array}{c}38.1 \% \\
\text { (vs. } 61.4 \%)\end{array}$ & $0.0256^{*}$ & & & & \\
\hline $\begin{array}{l}\text { Ferritin }>20,000 \mathrm{ng} / \mathrm{mL}^{* *} \\
(\mathrm{n}=26,50.6 \%)\end{array}$ & $\begin{array}{c}23.1 \% \% \\
\text { (vs. } 60.1 \%)\end{array}$ & $<0.001^{*}$ & & & $\begin{array}{c}1.99 \\
(1.1-3.6)\end{array}$ & $0.021^{*}$ \\
\hline $\begin{array}{l}\text { Fibrinogin }<150 \mathrm{mg} / \mathrm{dL} \\
(\mathrm{n}=45,35.6 \%)\end{array}$ & $\begin{array}{c}33.4 \% \\
\text { (vs. } 63.3 \%)\end{array}$ & $0.002 *$ & & & & \\
\hline \multicolumn{7}{|l|}{ Dynamic treatment response ${ }^{* *}$} \\
\hline Early stable responder $(n=42)$ & $87.0 \%$ & $<0.001^{*}$ & 1.0 & & & \\
\hline Late responder $(\mathrm{n}=36)$ & $73.7 \%$ & & $\begin{array}{c}1.73 \\
(0.6-5.2)\end{array}$ & 0.326 & & \\
\hline Unstable or non-responder ( $\mathrm{n}=44)$ & $0.0 \%$ & & $\begin{array}{c}17.3 \\
(6.5-45.9)\end{array}$ & $<0.001^{*}$ & & \\
\hline
\end{tabular}

OS: overall survival; HLH: hemophagocytic lymphohistiocytosis; HR: hazard ratio; EBV: Epstein-Barr virus; ${ }^{*} P<0.05 . * *$ Variables used in multivariate analyses were selected after excluding significant correlations: age, EBV-association, thrombocytopenia, hyperferritinemia, dynamic treatment response 
A

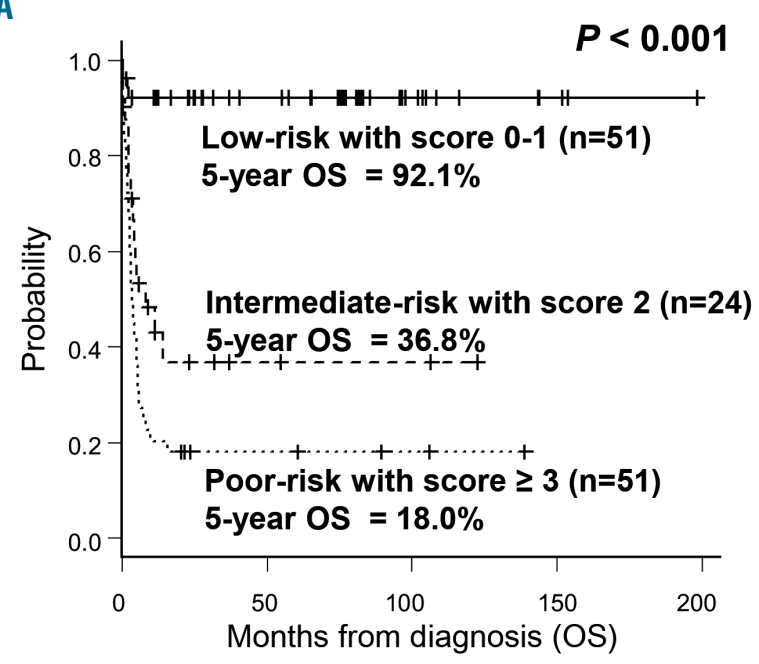

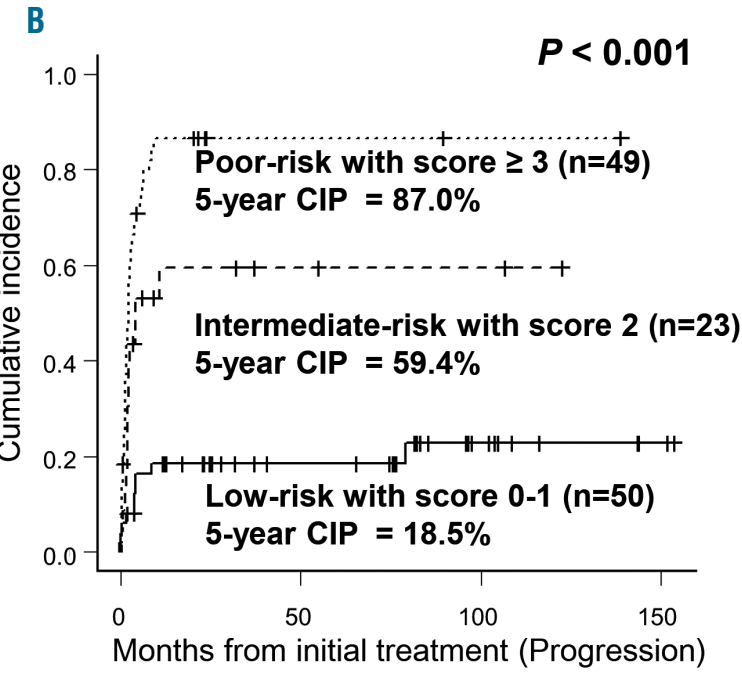

Figure 4. Survival outcomes according to hemophagocytic lymphohistiocytosis risk score. (A) Overall survival according to risk score. (B) Cumulative incidence of progression according to risk score. Low risk (score 0-1), intermediate risk (score 2), high risk (score $\geq 3$ ). OS: overall survival; CIP: cumulative incidence of progression.

patients according to variables such as age, thrombocytopenia, EBV-association, and high ferritin level, which were significant factors for poor overall survival in multivariate analysis. As we observed a high probability of relapse or refractory disease in high-risk patients, early intervention with salvage therapy and allogeneic HCT should be considered in selected patients. In contrast to high-risk or relapsed patients, we also observed patients who showed good responses to initial steroid therapy alone. Response to steroid alone was expected in some patients with an infection other than EBV, an autoimmune disease, or HLH of unknown cause. We may, therefore, consider delaying etoposide in some HLH patients without EBV and those with an autoimmune disease.

Although the distinction between primary and secondary HLH is obvious, several genetic abnormalities found in adult patients support the hypothesis that many cases of secondary HLH have an underlying genetic predisposition. ${ }^{34-36}$ This issue will remain challenging unless we can assess patients for the presence of genetic defects in every suspicious case, and more genes associated with cytotoxic function may be identified in the future. ${ }^{37}$ We were unable to check for all possible genetic abnormalities, except for some patients with negative results for UNC13D and PRF1 mutations, and we lack reference data regarding gene defects in adult patients. We, therefore, hypothesized that all enrolled patients without gene study data were cases of secondary HLH unless they did not satisfy HLH-2004 criteria. ${ }^{5}$ In addition, all patients enrolled in this study were diagnosed based on increased histiocytosis with active hemophagocytosis in a bone marrow study, although previous reports showed that $30 \%$ of HLH cases may not present with hemophagocytosis in an initial bone marrow study. ${ }^{3,38}$ Conversely, severely ill patients not satisfying the diagnostic criteria for HLH sometimes present with bone marrow hemophagocytosis. ${ }^{39}$ As we initially identified HLH patients based on bone marrow results, it is possible that we missed some HLH patients without evidence of bone marrow hemophagocytosis or who did not undergo a bone marrow examination.

HLH is a rare disease for which well-organized prospective studies are lacking: analysis of prognostic factors for secondary HLH is, therefore, difficult and few data are available for risk-stratification. Although our data originated from a retrospective study, patients were consistently treated and managed, and the number of patients was sufficient for the final analysis. As we excluded cases of malignancy-associated HLH, treatment response to protocols and survival outcomes were relevant for risk-stratification. Our prognostic risk model should be validated by larger studies. Combinations of several predictive factors at diagnosis and 8-week treatment response can allow clinicians to identify patients at high risk of disease progression, and second-line therapy including allogeneic HCT should be considered earlier in the course of treatment.

\section{Acknowledgments}

This study was supported by a grant from the National R\&D Program for Cancer Control, Ministry for Health and Welfare, Republic of Korea (1020370).

\section{References}

1. Janka GE. Familial and acquired hemophagocytic lymphohistiocytosis. Eur J Pediatr. 2007;166(2):95-109.

2. Janka GE. Familial and acquired hemophagocytic lymphohistiocytosis. Annu Rev Med. 2012;63:233-246.
3. Riviere S, Galicier L, Coppo P, et al. Reactive hemophagocytic syndrome in adults: a retrospective analysis of 162 patients. Am J Med. 2014;127(11):1118-1125.

4. Lee JS, Kang JH, Lee GK, Park HJ. Successful treatment of Epstein-Barr virus-associated hemophagocytic lymphohistiocytosis with HLH-94 protocol. J Korean Med Sci. 2005;20(2):209-214
5. Henter JI, Horne A, Arico M, et al. HLH2004: diagnostic and therapeutic guidelines for hemophagocytic lymphohistiocytosis. Pediatr Blood Cancer. 2007;48(2):124-131.

6. Trottestam H, Horne A, Arico M, et al Chemoimmunotherapy for hemophagocytic lymphohistiocytosis: long-term results of the HLH-94 treatment protocol. Blood. 2011;118(17):4577-4584. 
7. Takahashi N Chubachi A, Kume M, et al. A clinical analysis of 52 adult patients with hemophagocytic syndrome: the prognostic significance of the underlying diseases. Int J Hematol. 2001;74(2):209-213.

8. Li J, Wang O, Zheng W, et al. Hemophagocytic lymphohistiocytosis: clinical analysis of 103 adult patients. Medicine. 2014;93(2):100-105.

9. Imashuku S. Treatment of Epstein-Barr virus-related hemophagocytic lymphohistiocytosis (EBV-HLH); update 2010. J Pediatr Hematol Oncol. 2011;33(1):35-39.

10. Imashuku S, Tabata Y, Teramura T, Hibi S. Treatment strategies for Epstein-Barr virusassociated hemophagocytic lymphohistiocytosis (EBV-HLH). Leuk Lymphoma. 2000;39(1-2):37-49.

11. Kaito K, Kobayashi M, Katayama T, et al. Prognostic factors of hemophagocytic syndrome in adults: analysis of 34 cases. Eur J Haematol. 1997-59(4):247-253.

12. Milone MC, Tsai DE, Hodinka RL, et al. Treatment of primary Epstein-Barr virus infection in patients with X-linked lymphoproliferative disease using B-cell-directed therapy. Blood. 2005;105(3):994-996.

13. Henzan T, Nagafuii K, Tsukamoto $\mathrm{H}$, et al. Success with infliximab in treating refractory hemophagocytic lymphohistiocytosis. Am J Hematol. 2006;81(1):59-61.

14. Olin RL, Nichols KE, Naghashpour M, et al. Successful use of the anti-CD25 antibody daclizumab in an adult patient with hemophagocytic lymphohistiocytosis. Am J Hematol. 2008;83(9):747-749.

15. Shiraishi A, Ohga S, Doi T, et al. Treatment choice of immunotherapy or further chemotherapy for Epstein-Barr virus-associated hemophagocytic lymphohistiocytosis. Pediatr Blood Cancer. 2012;59(2):265-270.

16. Marsh RA, Allen CE, McClain KL, et al. Salvage therapy of refractory hemophagocytic lymphohistiocytosis with alemtuzumab. Pediatr Blood Cancer. 2013;60(1):101109

17. Chellapandian D, Das R, Zelley K, et al. Treatment of Epstein Barr virus-induced haemophagocytic lymphohistiocytosis with rituximab-containing chemo-immunotherapeutic regimens. Br J Haematol. 2013;162 (3):376-382.

18. Wang Y, Huang W, Hu L, et al. Multicenter study of combination DEP regimen as a salvage therapy for adult refractory hemophagocytic lymphohistiocytosis. Blood. 2015;126(19):2186-2192.
19. Henter JI, Samuelsson-Horne A, Arico M, et al. Treatment of hemophagocytic lymphohistiocytosis with HLH-94 immunochemotherapy and bone marrow transplantation. Blood. 2002;100(7):2367-2373.

20. Cooper N, Rao K, Gilmour K, et al. Stem cell transplantation with reduced-intensity conditioning for hemophagocytic lymphohistiocytosis. Blood. 2006;107(3):1233-1236.

21. Machaczka M, Nahi $H$, Karbach $H$ Klimkowska M, Hagglund H. Successful treatment of recurrent malignancy-associated hemophagocytic lymphohistiocytosis with a modified HLH-94 immunochemotherapy and allogeneic stem cell transplantation. Med Oncol. 2012;29(2): 1231-1236.

22. Henter JI, Elinder G, Ost A. Diagnostic guidelines for hemophagocytic lymphohistiocytosis. The FHL Study Group of the Histiocyte Society. Semin Oncol. 1991;18(1): 29-33.

23. Park KH, Park H, Kim M, Kim Y, Han K, Oh EJ. Evaluation of NK cell function by flowcytometric measurement and impedance based assay using real-time cell electronic sensing system. Biomed Res Int. 2013;2013:210726

24. Henter JI, Arico M, Egeler RM, et al. HLH94: a treatment protocol for hemophagocytic lymphohistiocytosis. HLH study group of the Histiocyte Society. Med Pediatr Oncol. 1997;28(5):342-347.

25. Parikh SA, Kapoor P, Letendre L, Kumar S, Wolanskyj AP. Prognostic factors and outcomes of adults with hemophagocytic lymphohistiocytosis. Mayo Clin Proc. 2014;89 (4):484-492

26. Imashuku S, Hibi S, Kuriyama K, et al. Management of severe neutropenia with cyclosporin during initial treatment of Epstein-Barr virus-related hemophagocytic lymphohistiocytosis. Leuk Lymphoma. 2000;36(3-4):339-346

27. Imashuku S, Hibi S, Ohara T, et al. Effective control of Epstein-Barr virus-related hemophagocytic lymphohistiocytosis with immunochemotherapy. Histiocyte Society. Blood. 1999:93(6):1869-1874.

28. Sullivan JL, Woda BA, Herrod HG, Koh G, Rivara FP, Mulder C. Epstein-Barr virus-associated hemophagocytic syndrome: virological and immunopathological studies. Blood. 1985;65(5):1097-1104.

29. Davis CL, Harrison KL, McVicar JP, Forg PJ, Bronner MP, Marsh CL. Antiviral prophylaxis and the Epstein Barr virus-related post- transplant lymphoproliferative disorder. Clin Transplant. 1995;9(1):53-59.

30. Balamuth NJ, Nichols KE, Paessler M Teachey DT. Use of rituximab in conjunction with immunosuppressive chemotherapy as a novel therapy for Epstein Barr virusassociated hemophagocytic lymphohistiocytosis. J Pediatr Hematol Oncol. 2007;29(8):569-573.

31. Strout MP, Seropian S, Berliner N Alemtuzumab as a bridge to allogeneic SCT in atypical hemophagocytic lymphohistiocytosis. Nat Rev Clin Oncol. 2010;7(7):415420

32. Gratama JW, Oosterveer MA, Zwaan FE, Lepoutre J, Klein G, Ernberg I. Eradication of Epstein-Barr virus by allogeneic bone marrow transplantation: implications for sites of viral latency. Proc Natl Acad Sci USA. 1988;85(22):8693-8696.

33. Ohga S, Kudo K, Ishii E, et al. Hematopoietic stem cell transplantation for familial hemophagocytic lymphohistiocytosis and Epstein-Barr virus-associated hemophagocytic lymphohistiocytosis in Japan. Pediatr Blood Cancer. 2010;54(2):299-306

34. Zhang K, Jordan MB, Marsh RA, et al. Hypomorphic mutations in PRF1 MUNC13-4, and STXBP2 are associated with adult-onset familial HLH. Blood. 2011;118(22):5794-5798.

35. Jordan $\mathrm{MB}$, Allen $\mathrm{CE}$, Weitzman $\mathrm{S}$, Filipovich AH, McClain KL. How I treat hemophagocytic lymphohistiocytosis. Blood. 2011;118(15):4041-4052

36. Zhang K, Chandrakasan S, Chapman $\mathrm{H}$, et al. Synergistic defects of different molecules in the cytotoxic pathway lead to clinical familial hemophagocytic lymphohistiocytosis. Blood. 2014;124(8):1331-1334

37. Filipovich AH. Hemophagocytic lymphohistiocytosis (HLH) and related disorders. Hematology Am Soc Hematol Educ Program. 2009;127-131.

38. Gupta A, Tyrrell P, Valani R, Benseler S Weitzman S, Abdelhaleem M. The role of the initial bone marrow aspirate in the diagnosis of hemophagocytic lymphohistiocytosis. Pediatr Blood Cancer. 2008;51(3):402404.

39. Strauss R, Neureiter D, Westenburger B Wehler M, Kirchner T, Hahn EG. Multifactorial risk analysis of bone marrow histiocytic hyperplasia with hemophagocytosis in critically ill medical patients--a postmortem clinicopathologic analysis. Crit Care Med. 2004;32(6):1316-1321. 